\title{
Internal Multidecadal and Interdecadal Climate Oscillations: Absence of Evidence Is No Evidence of Absence
}

\author{
Gisela Müller-Plath * \\ Department of Psychology and Ergonomics, Technische Universität Berlin, Berlin, Germany
}

Keywords: Pacific Decadal Oscillation, Atlantic Multidecadal Oscillation, sulfate aerosols, climate oscillations, multi-taper method of singular value decomposition spectral analysis (MTM-SVD), CMIP5 model simulation

\section{INTRODUCTION}

The present paper contributes a critical commentary on the recent finding by Mann, M. E., Steinman, B. A. and Miller, S. K (2020). Absence of internal multidecadal and interdecadal oscillations in climate model simulations. Nat. Commun. 11, 1-9.

Climate oscillations are recurring large-scale fluctuations in the surface temperatures of the oceans in connection with the atmosphere. This commentary focuses on the Pacific Decadal Oscillation (PDO, interdecadal timescale) and the Atlantic Multidecadal Oscillation (AMO, multidecadal timescale), which have been regarded as intrinsic climate drivers on the adjacent continents in numerous studies based on observations and paleoclimate reconstructions (Henley, 2017; O’Reilly et al., 2017). In a recent paper, Michael E. Mann and colleagues (Mann et al., 2020, hereafter M20) fail to find a PDO signal in global measured and modeled temperatures that is statistically different from noise. They further propose that the significant AMO-like signal is mainly due to anthropogenic aerosols in the 20th century, and to statistical artifacts before. Therefore they doubt the intrinsic nature of the two oscillations. The present paper shows that M20's results are largely artifacts themselves with issues ranging from using inadequate data and referencing improper literature on anthropogenic aerosols with regards to the AMO to inappropriately interpreting the results with regards to the PDO.

After briefly sketching the rationale and method of M20, I will elaborate on these three points.

M20 (p. 3) argue that any truly oscillatory AMO or PDO signals should generate a spatially coherent and large-scale variability pattern in the climate system with a narrowband signature in the frequency domain. They search for such signals in global (observed and modeled) temperature grids of different time lengths with the multi-taper method of singular value decomposition (MTM-SVD), which was developed and widely applied by Mann and Park (Mann and Park, 1994; Mann et al., 1995; Mann and Park, 1999). Significance tests of the test statistic LFV (local fractional variance) are carried out with Monte Carlo simulations generated according to the null hypothesis of colored (red) noise. The method can generally be applied to reconstruct the time course and the spatial pattern of any potential oscillatory climate signal.

Accepted: 04 November 2020

Published: 26 November 2020

Citation:

Müller-Plath G (2020) Internal

\section{INADEQUATE DATA}

M20 examine three global sets of temperature data for oscillatory signals, all spanning a minimum length of 158 years: Control simulations (control runs of the IPCC model ensemble CMIP5, using pre-industrial conditions of the atmosphere without any external forcing so that "any apparently 
oscillatory behavior must arise from internal variability"), historical observations (annualized global monthly average surface temperatures from the HadCRUT4 land and ocean surface temperature dataset), and historical simulations (IPCC model ensemble CMIP5, containing external anthropogenic and natural forcing). They find robust significant spectral peaks in the multidecadal AMO range (period 40-70 years) in the historical observations and the historical simulations, but not in the control simulations. However, the latter data set is the only one that covers a greater length of time, with almost half of the model runs spanning 500 years or more.

The absence of robust multidecadal AMO oscillations in the control simulations stands in sharp contrast to numerous studies finding the opposite in paleoclimatic data (Kerr, 2000; Gray et al., 2004; Chylek et al., 2011; Lanci and Hirt, 2015). Even with the same MTM-SVD method, the main author of M20 himself formerly identified robust and significant AMO frequencies in four independent sets of global proxy temperature data (Mann and Park, 1994). The most obvious explanation for the discrepancy is that control runs of the CMIP5 models have little to do with reality (Power et al., 2017). Since it is unclear to which extent the modeled "internal variability" reflects real conditions, the control simulations cannot be trusted unless their results were validated with paleoclimate data.

On the other hand, the historical observations and the historical simulations are insufficient in length in order to detect AMO frequencies with sufficient statistical power. They cover barely two cycles of the putative oscillation, which may span 80 years and more (Schlesinger and Ramankutty, 1994) and may consist of a broader band of low-frequency signals (O'Reilly et al., 2017; Sutton et al., 2018) than can be identified with the short time series. Furthermore, M20 leaves some confusion about the actual length of their control and historical simulations. Although they state in the text that a minimum length of 158 years is required and fulfilled by $\mathrm{N}=44$ control runs and $\mathrm{N}=118$ historical runs of the CMIP5 models, Table 1 in their Supplement reveals that only $\mathrm{N}=$ 42 (not 44) from the altogether $\mathrm{N}=47$ control simulations and only $\mathrm{N}=8$ (not 118 ) from the altogether $\mathrm{N}=164$ historical simulations satisfied the requirement of a minimum length of 158 years. So even though the latter data set showed a robust significant AMO frequency around a $\sim 45$ year period, other multidecadal frequencies might have been missed.

\section{IMPROPER LITERATURE REFERENCE}

Having found significant AMO frequencies only in the historical observations and simulations for the industrial time, M20 suggest that this multidecadal fluctuation is due to anthropogenic aerosols rather than to an intrinsic climate oscillation. They argue 1) that no multidecadal fluctuation is present under preindustrial conditions, 2) that in industrial times its phase is synchronized across three independent global time series, which would be unlikely if it were an intrinsic oscillation, whereas 3 ) the fluctuation with positive (warm) peaks near 1940 and 2000 and a negative (cool) peak near 1980 coincides with the response of the climate system to anthropogenic sulfate aerosol emissions. The first part of the argument is questioned above. The second refers to the observation that three global time series, namely two specific models and the historical observations, are roughly in phase (Figure 3 of M20). I agree with the authors that this would be unlikely if they were (stochastically) independent, but "internal"/"intrinsic" is not necessarily the same as "independent": The same phase points to a structural relationship, but it says nothing about whether its cause is external or internal to the climate system. For the third part of the argument, M20 refer to a recent paper by Kasoar et al. (2018). However, this referenced paper supports only the spatial correspondence of sulfate aerosol effects and the putative AMO signal, both emphasizing the North Atlantic region. With regard to the alleged temporal correspondence, the reader is referred to Figure 3 of M20, which not only leaves several questions open, but also ignores a substantial refutation in the literature: M20 do not provide enough detail to clearly understand what they are plotting in the time series of their Figure 3. Is it just one realization or an average of the two and five members that they have for the MPI-ESM-LR and HadGEM2-ES models? If it is the latter, they are methodologically canceling out any internal variability the model could show. If it is the former, on which criteria did they select the member, and do the rest behave similarly? Furthermore, in the MPI-ESM-LR model (Figure 3C of M20) the signal amplitude and the signal-tonoize ratio appear to be very low, which is reflected in the small percentage of explained variance. I doubt that this signal exceeds the statistical significance limit, which the authors do not comment on. Regarding the HadGEM2-ES model, Booth et al. showed already in 2012 that it closely reproduced the AMO-like multidecadal North Atlantic sea surface temperature (NASST) variability in the 20th century, and claimed that aerosols caused this variability. However, Zhang et al. (2013) refuted this claim on various methodological grounds, for example by comparing the heat content anomaly of the upper ocean in the North Atlantic with the HadGEM2-ES model with constant aerosols vs. all drivers, or by showing differences between observed and modeled spatial patterns of multi-decadal SST changes inside and outside the North Atlantic, and observed and modeled anomalies in salinity in the subpolar North Atlantic. Due to the large and multivariate discrepancies in the mechanisms, Zhang et al. concluded that the aerosol effects simulated by HadGEM2-ES cannot be responsible for the multi-decadal temperature variations observed in the North Atlantic in the 20th century. M20 make the same claim again now without mentioning this debate in the literature.

\section{INAPPROPRIATE INTERPRETATION}

In the interdecadal time range attributed to the PDO (16-20 years according to the authors), M20 found no robust significant spectral peaks in any of the three data sets. Again, this stands in sharp contrast to a large body of literature (for a review see e.g., Henley, 2017), including previous work by the main author using the same MTM-SVD method (Mann and Park, 1994). M20 explain the discrepancy by the time window being larger in their present than 


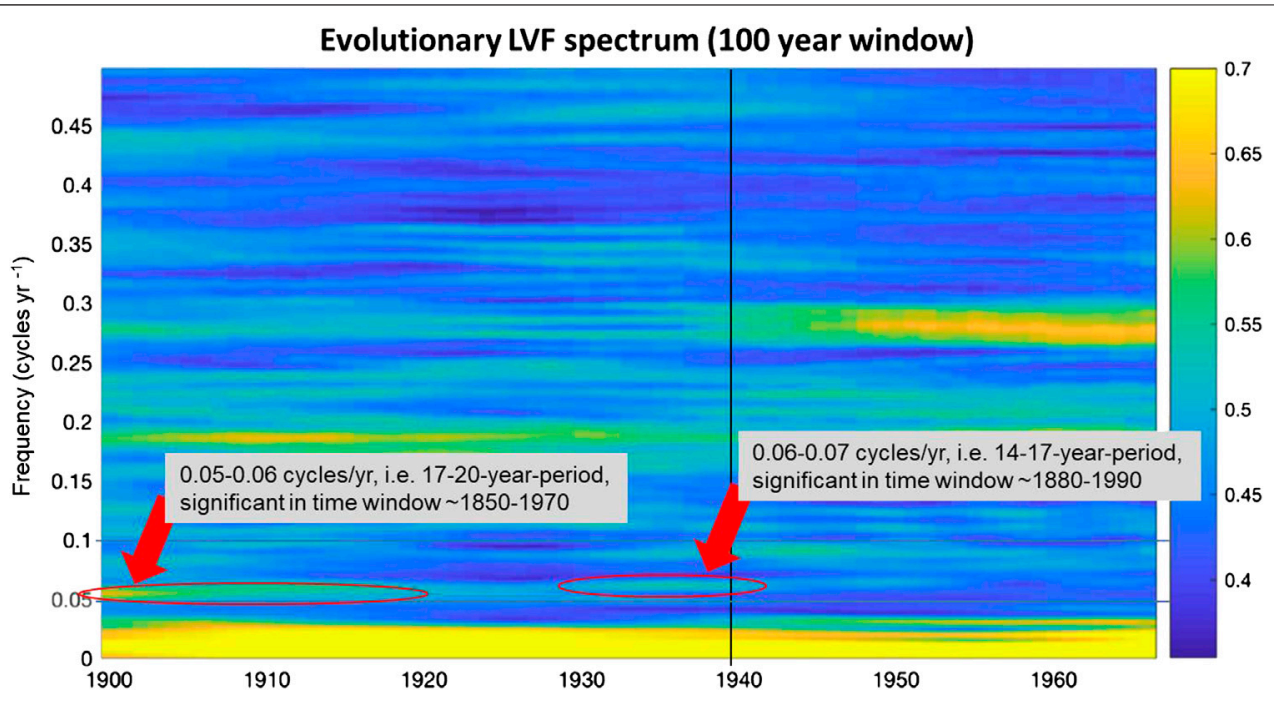

FIGURE 1 | Evolutionary spectra of historical observations in M20, using a moving window of 100 years length. The year at the horizontal axis represents the center of the 100 years moving window, with the vertical line indicating the window 1890-1990 analyzed by Mann and Park 1994. The colored scale depicts LVF values (In the 100 years time series in Mann and Park, 1994, LFV values exceeding roughly 0.53 were significant at $p<0.05$ level). The red arrows point to two slightly different frequencies showing up episodically significant and thereby supporting the view that the PDO is characterized by a rather broad and changing frequency band over time (Figure adapted from Mann et al., 2020, Supplementary Figure 2. Using the figure is permitted by the Creative Commons Attribution 4.0 International License).

in their former work, rendering the present results more reliable. However, on closer inspection the respective Supplementary Figure S2 in M20 suggests another interpretation: The moving window shows that the frequencies on the interdecadal scale are not constant over time - in other words, narrowband PDO oscillations are episodic (see Figure 1). This is fully consistent with the work of Folland et al. (2002), which M20 themselves mention in their introductory discussion on whether the PDO has a broad or narrow frequency band. However, with reference to their own former work (Mann and Park, 1994; Mann and Park, 1999) they decide a priori that the PDO is confined to a narrowband 16-20 year period. When they later find that this narrowband frequency is not robust over a larger time window, they conclude that there is no intrinsic PDO at all. However, a more appropriate interpretation would have been that their assumption of a continuous narrowband PDO frequency was premature and should be revised.

\section{REFERENCES}

Booth, B. B., Dunstone, N. J., Halloran, P. R., Andrews, T., and Bellouin, N. (2012). Aerosols implicated as a prime driver of twentieth-century North Atlantic climate variability. Nature 484, 228-232. doi:10.1038/nature10946

Chylek, P., Folland, C. K., Dijkstra, H. A., Lesins, G., and Dubey, M. K. (2011). Icecore data evidence for a prominent near 20 year time-scale of the Atlantic multidecadal oscillation. Geophys. Res. Lett. 38, L13704. doi:10.1029/ 2011GL047501

Folland, C. K., Renwick, J. A., Salinger, M. J., and Mullan, A. B. (2002). Relative influences of the interdecadal Pacific oscillation and ENSO on the South Pacific convergence zone. Geophys. Res. Lett. 29, 21-24. doi:10.1029/ 2001GL014201

\section{CONCLUSION}

Altogether, I conclude that the paper M20 is not advancing our understanding of the nature of multi- and interdecadal oscillations such as the AMO and PDO.

\section{AUTHOR CONTRIBUTIONS}

The author confirms being the sole contributor of this work and has approved it for publication.

\section{ACKNOWLEDGMENTS}

The author would like to thank a reviewer for valuable hints concerning argumentation and literature.

Gray, S. T., Graumlich, L. J., Betancourt, J. L., and Pederson, G. T. (2004). A tree ring based reconstruction of the Atlantic Multidecadal Oscillation since 1567 A.D. Geophys. Res. Lett. 31, L12205. doi:10.1029/2004GL019932

Henley, B. J. (2017). Pacific decadal climate variability: indices, patterns and tropical-extratropical interactions. Global Planet. Change 155, 42-55. doi:10. 1016/j.gloplacha.2017.06.004

Kasoar, M., Shawki, D., and Voulgarakis, A. (2018). Similar spatial patterns of global climate response to aerosols from different regions. Npj Clim. Atmos. Sci. 1, 1-8. doi:10.1038/s41612-018-0022-z

Kerr, R. A. (2000). A North Atlantic climate pacemaker for the centuries. Science 288, 1984-1985. doi:10.1126/science.288.5473.1984

Lanci, L., and Hirt, A. M. (2015). Evidence of Atlantic multidecadal oscillation in the magnetic properties of Alpine lakes during the last 2500 years. Palaeogeogr. Palaeoclimatol. Palaeoecol. 440, 47-52. doi:10.1016/j.palaeo.2015.08.040 
Mann, M. E., Park, J., and Bradley, R. S. (1995). Global interdecadal and centuryscale climate oscillations during the past five centuries. Nature 378, 266-270. doi:10.1038/378266a0

Mann, M. E., and Park, J. (1994). Global-scale modes of surface temperature variability on interannual to century timescales. J. Geophys. Res. 99, 25819-25833. doi:10.1029/94jd02396

Mann, M. E., and Park, J. (1999). Oscillatory spatiotemporal signal detection in climate studies: a multiple-taper spectral domain approach. Adv. Geophys. 41, 1-131. doi:10.1016/s0065-2687(08)60026-6

Mann, M. E., Steinman, B. A., and Miller, S. K. (2020). Absence of internal multidecadal and interdecadal oscillations in climate model simulations. Nat. Commun. 11, 1-9. doi:10.1038/s41467-019-13823-w

O'Reilly, C. H., Woollings, T., and Zanna, L. (2017). The dynamical influence of the Atlantic Multidecadal Oscillation on continental climate. J. Clim. 30, 7213-7230.

Power, S., Delage, F., Wang, G., Smith, I., and Kociuba, G. (2017). Apparent limitations in the ability of CMIP5 climate models to simulate recent multidecadal change in surface temperature: implications for global temperature projections. Clim. Dynam. 49, 53-69. doi:10.1007/s00382-016-3326-x
Schlesinger, M. E., and Ramankutty, N. (1994). An oscillation in the global climate system of period 65-70 years. Nature 367, 723-726. doi:10.1038/367723a0

Sutton, R. T., McCarthy, G. D., Robson, J., Sinha, B., Archibald, A. T., and Gray, L. J. (2018). Atlantic multidecadal variability and the U.K. ACSIS program. Bull. Am. Meteorol. Soc. 99, 415-425. doi:10.1175/bams-d-16-0266.1

Zhang, R., Delworth, T. L., Sutton, R., Hodson, D. L. R., Dixon, K. W., Held, I. M., et al. (2013). Have aerosols caused the observed Atlantic multidecadal variability? J. Atmos. Sci. 70, 1135-1144. doi:10.1175/jas-d-12-0331.1

Conflict of Interest: The author declare that the research was conducted in the absence of any commercial or financial relationships that could be construed as a potential conflict of interest.

Copyright (c) 2020 Müller-Plath. This is an open-access article distributed under the terms of the Creative Commons Attribution License (CC BY). The use, distribution or reproduction in other forums is permitted, provided the original author(s) and the copyright owner(s) are credited and that the original publication in this journal is cited, in accordance with accepted academic practice. No use, distribution or reproduction is permitted which does not comply with these terms. 